\title{
The Allocation of Resources to Education in Less Developed Countries
}

\author{
Gary S. Fields* \\ Yale University
}

\section{Introduction}

In the last few years, many less developed countries have suddenly and apparently to their surprise found themselves with too many (relative to the absorptive capacity of their economies) rather than too few workers with intermediate educational attainments. Yet, even as surpluses of educated workers grow larger and larger, the school systems continue to expand and the people continue to demand education. Elsewhere, ${ }^{1}$ we have sought to understand the persistence of a high demand for education in countries characterized by a substantial surplus of educated labor. In this paper, we construct a political model of the allocation of resources to education in less developed countries to try to explain why educational systems continue to grow in the face of such surpluses.

The specific plan of the paper is as follows. We begin in sect. 2 by briefly summarizing some of the available evidence on educational and labor market phenomena in less developed countries. In sect. 3, we offer a political model whereby more schools are constructed so long as the private demand for education exceeds the supply. Sect. 4 describes the path of adjustment toward and nature of equilibrium as predicted by our model. Finally, we conclude by considering some welfare and policy implications of the analysis.

At this point, we remark that the political model presented herein is in no way limited in applicability to the less developed countries. Although not within the scope of the present paper, a case could be made that a similar process has been taking place with respect to higher education in the United States. If so, the path of adjustment to equilibrium may lead to a somewhat different outcome from that predicted by social cost-benefit analyses or manpower forecasts.

\section{The labor market background of the growth of school systems}

A common belief in the last decade was the notion that unemployment in the less developed countries was largely of a structural nature due to the apparent shortage of skilled manpower. ${ }^{2}$ Besides helping to increase employment and accelerate economic growth, educational investment was also seen as a means of spreading desirable social values and needed skills. The people saw education as providing themselves and their children with the qualifications needed for the best jobs. ${ }^{3}$ By promoting an expansionary educational policy, elected politicians could appear to support the consensus

\footnotetext{
* Assistant Professor of Economics, Yale University. This paper is based on sections of my unpublished doctoral dissertation [Fields (1972)]. The preparation of the thesis was aided by the Rockefeller Foundation; the United States Agency for International Development; the Institute for Development Studies, University of Nairobi; and the Center for Research on Economic Development, University of Michigan. Thanks are extended to Professors Elliot J. Berg, George E. Johnson, Frank P. Stafford, and Lester D. Taylor for their invaluable criticisms and suggestions at all stages of the thesis research. Finally, I wish to thank Joseph E. Stiglitz for his helpful comments on an earlier draft of this paper.

1 Fields (1973).

2 The general mood of the time is conveyed in Harbison and Myers (1964).

${ }^{3}$ It is in the sense of families seeking to have their children educated that we shall talk about the demand for education. More specifically, throughout this paper, we shall use the term 'demand for education' to mean the number of persons who would like (or whose parents wish them) to be enrolled
} 
development strategy and represent the wishes of their constituents and thereby remain in everyone's favor. ${ }^{4}$ The result of the interaction between the strong popular demand for education and the acquiescence of the educational planners was the rapid growth of school systems in the less developed countries during the sixties. ${ }^{5}$

Partly as a result of the rapid growth of school systems and in contrast to the skilled manpower shortages of the last decade, many more educated people are now being produced than can be absorbed into employment which fully utilizes their skills. The problem is not new - India has had surplus educated labor for years and the now classic article by Callaway (1963) pointed out this phenomenon in Africa ten years ago - but what is new is the scope. Many of the surplus educated accept lower-level jobs ${ }^{6}$ but education-unemployment profiles for a number of less developed countries reveal that unemployment rates are highest for persons with intermediate educational attainment. ${ }^{7}$

Our concern in this paper is to understand why additional public resources continue to be allocated to education in these circumstances. One possible explanation is that the planning authorities have in effect weighed the social costs and benefits of education and decided that expansion is justified despite considerable unemployment amongst the educated. My own view is that the continued expansion of educational systems which we observe in the face of inadequate absorption of educated workers in the labor market does not seem to be explained adequately by considerations of the economic benefits to society. ${ }^{8}$ In the remainder of this paper, we set forth and consider the implications of an alternative allocative mechanism.

\section{A political interpretation of the supply of education}

We postulate that the 'education explosion' in many less developed countries has a simple political explanation. If the marginal social returns to educational investment are low when there are already surplus educated who are unemployed, optimal education policy would dictate the contraction of school systems. This would free scarce capital for investment or for the production of non-educational output and also lower the cost of financial aid to students, thereby reducing the pressure on the government's budgetary resources or on taxpayers.

However, there may be important political forces exerting pressure for a larger educational establishment, irregardless of the size of the social returns. These include parents who want more education for their children, teachers' unions with

in school under existing conditions and who are able to pay the direct costs of schooling.

${ }^{4}$ There is a significant exception to this generalization. One group that would be likely to oppose expansion of the educational system are those already educated who are unemployed. This is because any additional educated workers would enter into competition for the jobs which the educated unemployed are already seeking. However, the educated unemployed are far fewer in numbers than all those supporting a larger schooling system and we shall ignore those people subsequently.

5 For a discussion of the so-called 'education explosion', see Bereday and Lauwerys (1965); for figures in various parts of the world, see UNESCO (1970, pp. 62-67).

It is important to realize that in most less developed countries the schools and colleges are constructed, operated, and financed largely by the central government. Furthermore, the amount of financial aid to students is not trivial, since students in primary and secondary education are generally charged only a small fraction of the costs of their schooling and higher education is frequently entirely subsidized. As a result, educational expenditure is probably the largest single item in the budgets of most less developed countries (primarily those in Latin America and Sub-Saharan Africa), and second in importance behind military expenditures in most others (primarily in the Mideast and Southeast Asia). See U.N. (1972, pp. 656737).

${ }^{6}$ See OECD (1969).

${ }^{7}$ For evidence on this point from various parts of the Third World, see Turnham (1971, p. 51) and Blaug (1973, pp. 7-11).

${ }^{8}$ In this paper we will not seek to evaluate the possible merits or costs of continued educational expansion under these conditions. Many of the issues involved are raised in Fields (1972). For more recent discussions of the possible economic values of education, see Stiglitz (1973, Arrow (1973), and Blaug (1973). 
a large vested interest in the size of the educational establishment, and employers who wish to hire the relatively welleducated. Each of these groups would be perfectly rational in considering the private gains they would expect to realize from a larger educational system in relation to the private costs and expressing their views in the political arena. For obvious reasons, teachers and employers would expect to gain more from a larger educational system than it would cost them. But what about ordinary citizens? There are at least four reasons why they might want a large educational system. (1) They may be nearsighted and fail to connect lower output of other public goods or higher taxes with a large educational system. (2) Even if they correctly perceive the costs, each parent may be over-optimistic about the likelihood that his particular child will be admitted to the next level of schooling. (3) Even if there are no misperceptions of costs or likelihood of receiving benefits, parents may be gamblers and be willing to take risks (i.e., pay higher taxes) even if there is only a small chance of receiving the high private return, which is conditional upon his child being able to go on. ${ }^{9}(4)$ Finally, even if parents are not gamblers, investment in education in less developed countries yields very high private returns despite substantial unemployment and underemployment amongst the educated, and a space in school therefore has a large monetary value. As we have noted earlier, educational systems in less developed countries typically are heavily if not entirely subsidized so that the private costs are small. Furthermore, each step in the educational ladder roughly doubles one's lifetime earnings. As a consequence, private rates of return to investment in education in less developed countries generally are on the order of $20 \%$ per year or more. ${ }^{10}$

For all these reasons, there is cause to believe that a demand for education in excess of the supply is a politically unstable situation. It would seem that given the political nature of the demand for education and the strength of feeling behind it, rather than contracting school systems in response if social returns are low, politicians could help secure their positions ${ }^{11}$ by moving in the opposite direction and using their influence to expand the school system. Hence, we postulate a simple adjustment process, namely, that supply adjusts according to the relation

$$
\Delta S=\eta(D-S), \quad \eta<1
$$

i.e., during any period of time, the number of new schooling spaces being built $(\Delta S)$ is some fraction $\eta$ of the difference between demand $(D)$ and supply $(S)$ at the beginning of the period. The coefficient of adjustment may be assumed to vary positively with society's taste for education, positively with the level of national income, and negatively with the cost of constructing and operating schools. In short, what we have is teachers, employers, and ordinary citizens facing one set of signals - high private rates of return - and the political system responding to those same private signals while failing to take into account the social rate of return to additional educational investment, which may be quite small.

\section{Demand and supply of education and the nature of equilibrium}

If the supply of education is determined politically in the manner just described, when does expansion end? From the

\footnotetext{
9 An interesting bit of evidence along these lines is the reaction of parents in former British colonies to the proposed replacement of the traditional British curriculum by a program emphasizing vocational and agricultural education. The parents apparently felt that such a curriculum would effectively exclude their children from university and were unwilling to risk not winning the big payoff.

10 See Psacharopoulos (1973, p. 62).

11 This is sometimes expressed negatively: that failure to expand educational opportunities is tantamount to political suicide.
} 
supply adjustment relation (1), it is clear that our political model implies that the supply of education stops changing only if the demand and supply of education are equal. The condition

$$
D=S \Leftrightarrow \Delta S=0
$$

is thus necessary for static equilibrium in the market for education.

This condition $\Delta S=0$ is not sufficient for a stable equilibrium. Viewed in a dynamic context, anything that would systematically alter the demand for education would also disrupt any static equilibrium in which condition (2) may have been temporarily satisfied. In particular, the stock of persons being educated today corresponds to the inflow of educated persons into the labor force tomorrow. Unless the inflow is exactly equal to the outflow of educated persons on account of death or retirement, the size of the educated labor force will change. This will alter employment conditions and change the private rate of return and the quantity of education demanded.

Changes in other economic variables would have the effect of shifting the entire demand for education schedule. These factors include net population growth, changes in the skilled-unskilled relative wage ratio, non-neutral technological change, and changes in the composition of the relative demand for workers of different educational attainments. We shall hold these factors constant and consider in a partial analysis the path of adjustment to equilibrium.

The change in the educated labor force $\left(\Delta \mathrm{L}_{\mathrm{E}}\right)$ is the inflow of newly-educated persons $I=\min (S, D)$ minus the outflow from the labor force, which is the death and retirement rate $(\delta)$ times the educated labor force $\left(L_{E}\right)$ :

$$
\Delta L_{E}=I-\delta L_{E}
$$

In order to keep employment conditions constant, $L_{E}$ must remain unchanged. Thus, the condition

$$
I=\delta L_{E} \Leftrightarrow \Delta L_{E}=0
$$

is necessary for dynamic equilibrium in the market for education.

When condition (2) is satisfied, there is no tendency for the supply of education to change. Similarly, when condition (4) is satisfied, under the conditions described above, there is no tendency for the stock of educated people to change. But since the demand for education depends on the number of educated people, when eq. (4) is satisfied, the quantity of education demanded also remains constant. Therefore, eqs. (2) and (4) together constitute a set of necessary and sufficient conditions for equilibrium in the market for education.

Let us consider an economy which initially has an excess demand for education (disequilibrium in the education market) and which is experiencing a growing surplus of educated workers (disequilibrium in the labor market). Such an economy is illustrated in fig. 1.

In fig. 1, the demand for education is drawn as a downward sloping function of the number of persons educated. This shape is consistent with either flexible or rigid wages. If wage rates are flexible, this shape may be explained by the fact that an additional supply of education lowers the wage received by educated workers, which in turn-lowers the private rate of return to investment in education. If instead wages are considered to be fixed, the intuitive justification for the downward-sloping relation is that a larger number of, say, university graduates in the labor market lowers the expected income of each by reducing the probability that any particular one will be the next highly-paid university president, business executive, or whatever. Elsewhere, I have shown that under several alternative labor market constructs, the demand for education would not be expected to decline smoothly [see Fields (1973)]. However, the monotonically 
declining relation drawn in fig. 1 eases exposition without affecting the nature of the final equilibrium or the process of adjustment to it.

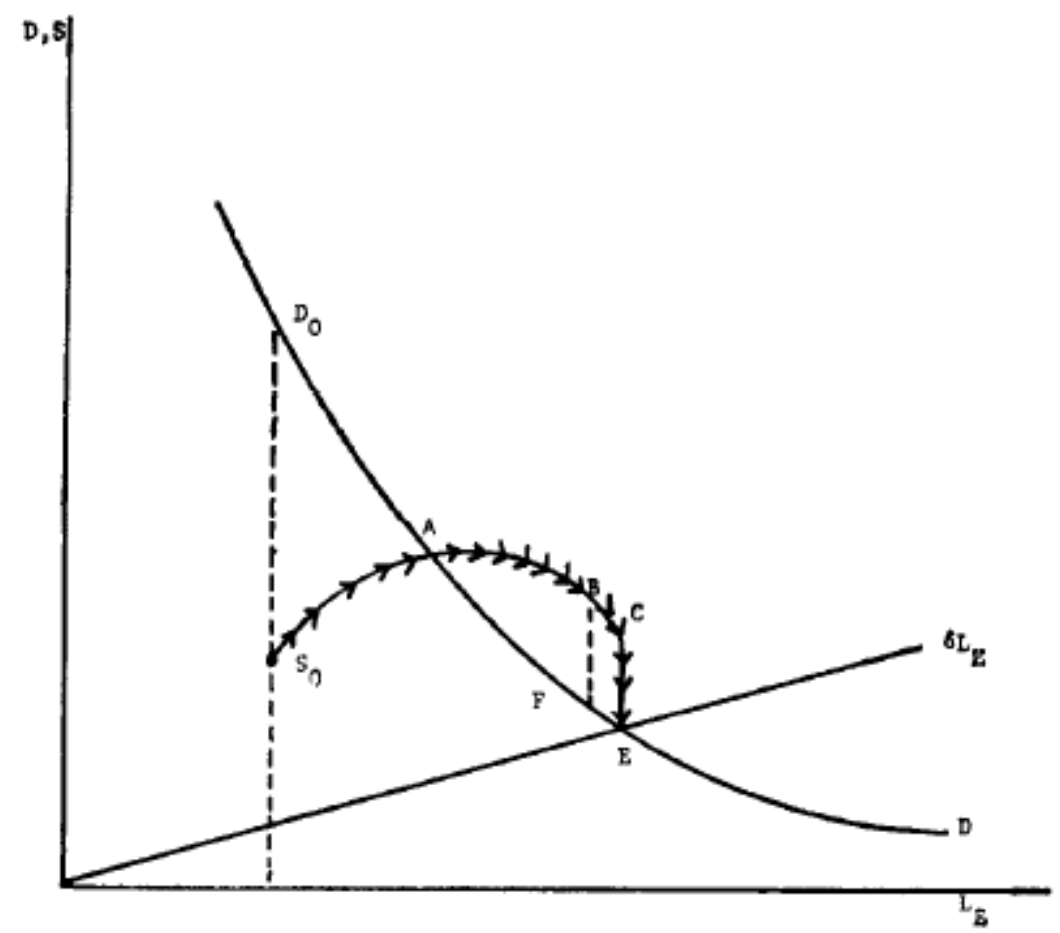

Fig. 1. The supply and demand for education and adjustment to equilibrium.

The initial excess demand for education is the gap between $D_{0}$ and $S_{0}$. The existence of a growing surplus of educated workers is illustrated by the inflow to the educated labor force $\left(I_{0}=S_{0}\right)$ lying above the outflow $\left(\delta L_{E}\right)$.

Because the demand for education is greater than the supply, by eq. (1), the political mechanism would cause the educational system to expand. The fact that the number of new entrants to the educated labor force is greater than the outflow due to death and retirement implies, by eq. (3), that $L_{E}$ is increasing. In the rigid wage case, this lowers the probability of finding a skilled job. In the flexible wage case, the wage actually paid to educated workers is reduced. Thus, in either circumstance, the demand for education will fall. The growing supply of education and falling demand for it are shown in fig. 1 by the respective positive and negative slopes of the $S$ and $D$ curves. Since the difference between demand and supply is narrowing, the change in supply gets smaller as the number of persons educated increases. Therefore, the supply increases at a diminishing rate, illustrated by the flattening of the supply function between $S_{0}$ and $A$. At point $A$, the demand and supply of education are equal and $\Delta S=0$.

In the past, some writers (including myself) have looked only as far as $A$. Although this point satisfies the condition for a static equilibrium in the market for education eq. (2), it is not a dynamically stable equilibrium. This is because at $A$ the number of newly-educated workers is greater than the number leaving the labor force. Thus, the educated labor force $\left(L_{\mathrm{E}}\right)$ is growing, which implies a systematic rightward tendency and a continued deterioration in the labor market prospects for educated workers. As a result, the demand for education will fall beneath the supply, creating excess capacity in the schools and leading to a reduction in their number. ${ }^{12}$ Since there is only partial adjustment $(\delta<1)$, the supply contracts

12 The financial difficulties of many colleges and universities in the United States at the present time may foreshadow just such a contradiction as 
slowly at first (between $A$ and $B$ ). The excess supply increases and reaches a maximum (at $B F$ ), after which supply decreases faster than demand. As this occurs, the inflow of newly-educated workers into the labor force becomes more equal to the outflow on account of death and retirement. At point $C$, condition (4) for equilibrium in the education market is approximately satisfied. However, at $C$, the supply of education exceeds the demand; therefore, condition (2) is not satisfied. Hence, the supply of education is contracted and gradually the excess capacity in the schools is eliminated. We therefore move down an approximately vertical path on the graph, approaching equilibrium at $E$, where the supply and demand for education are again equal and the flows into and out of the educated labor force are also equal.

The equilibrium at $E$ may readily be shown to be a stable one. A small movement away from $E$ could take us into one of four possible zones, labeled I-IV in fig. 2. Relations (1) and (3) give the following adjustment tendencies, illustrated by arrows in the figure:

\begin{tabular}{cll} 
Zone & Relation of $S$ to $D$ & Relation of $I$ to $\delta L_{\mathrm{E}}$ \\
\hline I & $S<D \Rightarrow S$ rising & $I<\delta L_{\mathrm{E}} \Rightarrow L_{\mathrm{E}}$ rising \\
II & $S>D \Rightarrow S$ falling & $I>\delta L_{\mathrm{E}} \Rightarrow L_{\mathrm{E}}$ rising \\
III & $S>D \Rightarrow S$ falling & $I<\delta L_{\mathrm{E}} \Rightarrow L_{\mathrm{E}}$ falling \\
IV & $S<D \Rightarrow S$ rising & $I<\delta L_{\mathrm{E}} \Rightarrow L_{\mathrm{E}}$ falling \\
\hline
\end{tabular}

The adjustment path shown in fig. 1 demonstrates that from a point in zones I or II, the economy will move toward $E$. Returning to fig. 2, if we begin from a point such as $J$ in zone III, the economy might move directly to equilibrium along

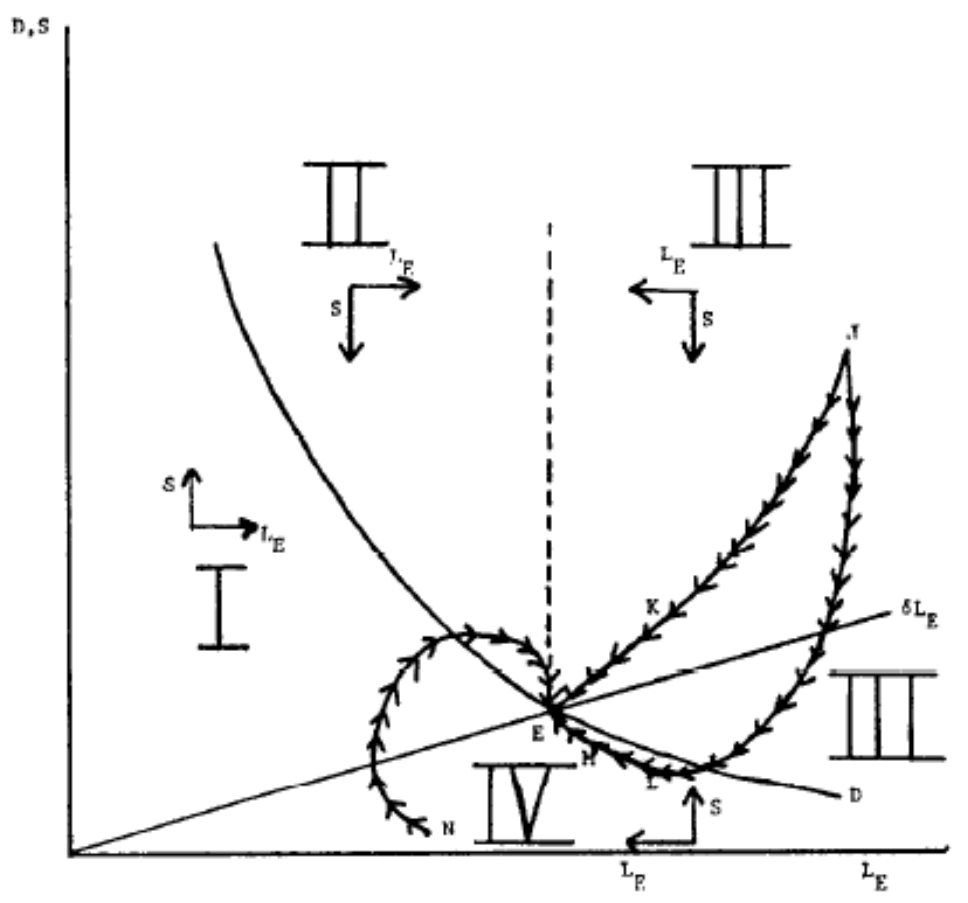

Fig. 2. Stability of equilibrium.

path $J K E$, or indirectly along path $J L M E$. In either case, the equilibrating forces return the economy to $E$ from anywhere in zone III. Finally in zone IV, there are some points such as $M$ from which the economy would go directly to $E$ and others 
such as $N$ which will take a more circuitous path. In any event, we have shown that movement toward $E$ takes place for any possible perturbation so $E$ is in fact a stable equilibrium as we set out to prove.

The analysis may be amended to take into account the possibility that in addition to altering the supply of education in response to an excess demand for schooling spaces, politicians may also seek to reduce the excess demand by altering the parameters which enter into the individual's computations of private costs and benefits. This might be done by raising the private cost of education by means of increased school fees, by lowering the benefits by reducing the size of the educateduneducated earnings differential by means of an incomes policy, or by erecting capital market barriers to prevent potential students from raising the requisite funds. Politicians might also seek to lower the entire demand for education function by ceasing to stimulate people's tastes for education. If we consider one demand function $D_{1}$ on the assumption of given costs, wage differentials, capital market conditions, and tastes and another $D_{2}$ assuming that politicians act to reduce the demand for education in any or all of the ways mentioned above, by tracing a supply adjustment mechanism of the type shown in fig. 1 , it can easily be shown that $D_{2}$ would lead to a lower peak supply and lower equilibrium supply than $D_{1}$.

The most noteworthy feature of the interaction between privately-motivated demand for education and politicallydetermined supply is that, as equilibrium is approached, school systems would be expected at first to expand, although a halt or even contraction may be anticipated later. It might well be asked what it is about our model which moves the economy toward equilibrium in this roundabout way. If the ultimate equilibrium is at $E$, why would vote-maximizing politicians not anticipate the future direction and simply move directly there? The answer to this is that they are maximizing votes at the time and if they get too far ahead of the electorate they would lose voter support. What we have here is a situation which in a formal sense closely resembles the behavior postulated in physical capital models and which embodies many of the same stock-flow interactions. Even if a firm has reason to believe that there will be a business downturn five years hence and it will then require a smaller capital stock than it now has, it would not make sense to disinvest now if it also anticipates a boom over the next few years. In like manner, politicians probably see the current excess demand for education and respond to that and expect that they will worry about surplus school spaces when and if the situation arises. Far from being myopic, they seem to have the best chance of being in office in the future if they take steps to increase their current popularity. As in physical capital models in which seemingly rational maximizing behavior leads to marked cycles in inventory investment, ${ }^{13}$ so maximizing behavior in our human capital model leads us to expect first an increase and then a reduction in human capital investment.

The fact that adjustment to equilibrium leads first to an expansion and then a contraction of school systems gives us reason to believe that the education explosion is not a permanent feature in less developed countries. Despite this predicted trend, the slowdown may nonetheless take a long time and entail a costly overcommitment of resources to education in the meantime. Furthermore, demand-reducing policies which limit the availability of education to the poorest segments of the population could also be introduced in the interim, with important implications for the distribution of income. In the final section, we consider some consequences of these and other predictions of our model.

\footnotetext{
13 See, for instance, Lovell (1964).
} 


\section{Conclusion}

In this paper, we have suggested the possibility that the allocation of resources to education in less developed countries might be viewed as the result of political decisions rather than as the outcome of a social cost-benefit calculation. Such an allocative process has at least three important consequences for the development paths of the countries involved.

First, if the political mechanism is correct, educational supply decisions in less developed countries would not seem to reflect a conscious social choice as to what is the best use of a country's scarce resources. While one may question whether a social rate of return as conventionally computed is a meaningful guide to educational decisions, there can be little disagreement about the inadequacy of an allocative mechanism which does not seek to weigh the social gains from education in relation to the social costs of supplying it. Yet, the political model described in this paper is exactly such a mechanism, since it postulates that educational decisions in less developed countries are made with reference to private costs and benefits. Since there is reason to believe that these do not coincide with the social costs and benefits, it is hard to imagine that decisions made in this way would turn out to be optimal.

Second, the political model, which we have considered leads us to expect an expansion of the schooling system in the short run despite unemployment and underemployment amongst the educated. The importance of this lies in the fact that governments in the less developed countries are the major source of national savings and investment. Any additional competing claims on governmental budgets would likely divert resources from important and socially profitable public projects, thereby reducing savings and investment and leading to a slower rate of economic growth. Thus, the allocation of resources to education by political forces raises important questions of efficiency.

Third, the political forces we have described also have important consequences for the distribution of income. We have noted that the political response to an excess demand for education might not only be to take steps to raise the supply closer to the private demand but also to take action to lessen the demand. One such action might be to reduce the expected private benefits of education by narrowing the skilled-unskilled wage differential, either through higher taxes or a slower rate of growth of upper-level incomes. A lower wage would be expected to lead to more jobs and more output, provided there are no strongly adverse effects on worker efficiency or turnover. Not only would we expect there to be a larger pie to divide but we might reasonably expect it to be divided among more people. However, contrary to this seemingly beneficial effect, there might well be other and less favorable outcomes of demand-reducing policies. Higher school fees, erection of (or failure to remove) capital market barriers, and measures to shift people's tastes for education would all act to limit the private demand for education. And it would be the poor people who, for reasons that such diverse economists as Becker (1967) and Bowles (1971) seem to agree on, would be hit the hardest. Since education is of great importance in determining one's income position in a less developed country, the new incentive structure and opportunities for acquiring education would, by making education prohibitively costly to the children of the poor, tend to perpetuate existing income inequalities and maintain the position of those at the top.

These considerations suggest that in situations where educational supply choices are made by politicians whose very tenure in office depends on satisfying popular demands, the risk of potentially harmful effects on growth and income distribution will be present, unless the power to make decisions on educational matters is transferred to a body which is relatively insulated from political pressure. 


\section{References}

Arrow, K.J., 1973, Higher education as a filter, Journal of Public Economics 2, 193-216.

Bereday, G.Z.F. and J.A. Lauwerys, 1965, The education explosion (Evans Brothers Ltd., London).

Becker, G.S., 1967, Human capital and the personal distribution of income, W.S. Woytinsky Lecture no. 1 (Department of Economics and Institute of Public Administration, University of Michigan, Ann Arbor, Mich.).

Blaug, M., 1973, Education and the employment problem in developing countries (International Labour Office, Geneva).

Bowles, S., 1971, Unequal education and the reproduction of the social division of labor, The Review of Radical Political Economics, Fall/Winter, 1-30.

Callaway, A.C., 1963, Unemployment among African school leavers, Journal of Modern Africa Studies 3, 351-371.

Fields, G.S., 1972, A theory of education and labor markets in less developed countries, unpublished doctoral dissertation (Department of Economics, University of Michigan, Ann Arbor, Mich.).

Fields, G.S., 1973, The private demand for education in relation to labor market conditions in less developed countries, Discussion Paper 160, rev. ed. (Economic Growth Center, Yale University, New Haven, Conn.).

Harbison, F. and C.A. Myers, 1964, Education, manpower and economic growth (McGraw- Hill, New York).

Lovell, M., 1964, Determinants of inventory investment, in: National Bureau of Economic Research, Models of income determination, vol. 28 (Princeton University Press, Princeton, N.J.) 177-232.

Organisation for Economic Co-operation and Development, 1969, Statistics of the occupational and educational structure of the labour force in 53 countries (OECD, Paris).

Psacharopoulos, G., 1973, Returns to education: An international comparison (Elsevier- North-Holland, Amsterdam).

Stiglitz, J.E., 1973, The theory of'screening', education, and the distribution of income, Cowles Foundation Discussion Paper 354 (Yale University, New Haven, Conn.).

Turnham, D., 1971, The employment problem in less developed countries (OECD, Paris).

UNESCO, 1970, UNESCO Statistical Yearbook 1970 (Paris) 62-67.

United Nations, 1972, Statistical Yearbook 1972 (U.N., New York). 